\title{
Cardiac hormones are potent inhibitors of secreted frizzled-related protein-3 in human cancer cells
}

\author{
WILLIAM P. SKELTON IV ${ }^{1,2}$, MICHELLE SKELTON ${ }^{1}$ and DAVID L. VESELY ${ }^{1}$ \\ ${ }^{1}$ Departments of Medicine, Molecular Pharmacology and Physiology, James A. Haley Veterans Administration \\ Medical Center and University of South Florida Morsani Health Sciences Center, Tampa, FL 33612, USA
}

Received September 6, 2012; Accepted October 29, 2012

DOI: $10.3892 /$ etm.2012.806

\begin{abstract}
Secreted frizzled-related proteins (sFRPs) are secreted glycoproteins involved in neoplastic growth. Four hormones synthesized in the heart, namely vessel dilator, atrial natriuretic peptide (ANP), kaliuretic peptide (KP) and long-acting natriuretic peptide (LANP), have anticancer effects both in vitro and in vivo. These heart hormones were evaluated for their ability to inhibit sFRP-3, which is associated with tumor invasiveness, in human pancreatic cancer, colorectal cancer and renal adenocarcinoma cell lines. Vessel dilator, KP, ANP and LANP maximally reduced the concentration of sFRP-3 by $83 \%, 83 \%, 84 \%$ and $83 \%$, respectively (each at $\mathrm{P}<0.0001$ ), in the human colorectal adenocarcinoma cells. In the human pancreatic carcinoma cells, the concentration of sFRP-3 was maximally reduced by $77 \%, 77 \%, 77 \%$ and $78 \%$ (each at $\mathrm{P}<0.0001$ ) secondary to treatment with vessel dilator, KP, ANP and LANP, respectively. In the human renal adenocarcinoma cells, the sFRP-3 was maximally reduced by vessel dilator, KP, ANP and LANP by 68\%, 66\%, 68\% and $66 \%$ (each at $\mathrm{P}<0.0001$ ), respectively. The results indicate that these four cardiac hormones are significant inhibitors (up to $84 \%$ ) of sFRP-3 in a variety of human cancer cells. Furthermore, these data suggest that the metabolic targeting of sFRP-3 by the cardiac hormones contributes to their anticancer mechanism(s) of action.
\end{abstract}

\section{Introduction}

Secreted frizzled-related proteins (sFRPs) are palmitoylated secreted glycoproteins that are involved in cell proliferation

Correspondence to: Dr David L. Vesely, Molecular Pharmacology and Physiology, J. A. Haley Veterans Administration Medical Center-151, 13000 Bruce B. Downs Blvd., Tampa, Florida 33612, USA

E-mail: david.vesely@va.gov

Present address: ${ }^{2}$ University of Florida College of Medicine, 1600 SW Archer Road, Gainesville, Florida 32608, USA

Key words: secreted frizzled-related protein 3, cardiac hormones, colorectal adenocarcinoma, pancreatic carcinoma, renal adenocarcinoma and neoplastic growth $(1,2)$. sFRPs consist of $\sim 300$ amino acids and are composed of a cysteine-rich domain (CRD) at their amino terminal ends with $30-50 \%$ homology to the active site of the Frizzled receptor $(3,4)$. The CRD of Frizzled serves as the active site for Wnt binding and subsequent signal transduction. This class of CRD is conserved in diverse proteins, including the seven-transmembrane class of tyrosine receptor kinases of the receptor tyrosine kinase-like orphan receptor (ROR) family (5). sFRPs act as extracellular signaling ligands and are able to downregulate Wnt signaling by forming an inhibiting complex with the Frizzled receptors (6). Since Wnt causes cancer cells to grow, it was originally hypothesized that sFRPs are inhibitors of cancer cell growth (7) but a subsequent study revealed that sFRP-3 (also known as FrzB) is present at high levels in metastatic renal cancer tissues (8). This study also demonstrated that sFRP-3 promotes invasion by renal cancer cells (8). sFRPs have been linked to tumor-promoting activities in other types of cancer (9). The elevated levels of SFRP-3 in various types of cancer suggest that it may be a valuable therapeutic target (7).

Four endogenous cardiac hormones [vessel dilator, kaliuretic peptide (KP), atrial natriuretic peptide (ANP) and long-acting natriuretic peptide (LANP)] have anticancer effects in vivo (10-12), and in vitro have been reported to decrease the numbers of human renal carcinoma cells by up to $81 \%$ (13), human colorectal cancer cells by $89-97 \%$ (14) and pancreatic cancer cells by up to $65 \%$ (15). The present investigation was designed to determine whether the four cardiac hormones inhibit sFRP-3 in human renal carcinoma, human pancreatic cancer and human colorectal cancer cells as part of their anticancer mechanism(s) of action. The results showed that each of the four cardiac hormones potently inhibited SFRP-3 in the three different types of cancer.

\section{Materials and methods}

Cardiac hormones. The four cardiac hormones were obtained from Phoenix Pharmaceuticals, Inc. (Belmont, CA, USA).

Human colorectal, pancreatic and renal cancer cells. Human colorectal cancer (ATCC number CCL-225), pancreatic carcinoma (ATCC number CRL-1469, panc-1) and renal adenocarcinoma (CRL-1611) cells were obtained from American Type Culture Collection (ATCC; Manassas, VA, 
USA). The ATCC authenticated these cell lines and performed the genotype and phenotype evaluations, including DNA profiles (STR) and cytogenetic analyses.

Culturing of human colorectal adenocarcinoma cells. The propagation of the human colorectal adenocarcinoma cells was performed in Roswell Park Memorial Institute (RPMI)-1640 medium with $2 \mathrm{mM}$ glutamine adjusted with the addition of $1.5 \mathrm{~g} / 1$ sodium bicarbonate, $4.5 \mathrm{~g} / 1$ glucose, $10 \mathrm{mM}$ HEPES, $1 \mathrm{mM} 90 \%$ sodium pyruvate and $10 \%$ fetal bovine serum (FBS; Sigma Chemical Co., St. Louis, MO, USA) at a temperature of $37^{\circ} \mathrm{C}$ with $5 \% \mathrm{CO}_{2}$ as recommended by the ATCC. Cells were dispensed into new flasks with sub-culturing every 6-8 days. The growth medium was changed every three days.

Culturing of human pancreatic carcinoma cells. The propagation of the human pancreatic carcinoma cells was carried out in Dulbecco's modified Eagle's plus Ham's F12A 1:1 mixture containing $1.2 \mathrm{~g} / 1$ sodium bicarbonate (Sigma Chemical Co.) supplemented with 15 mM HEPES and FBS $10 \%$ with 5\% $\mathrm{CO}_{2}$ at a temperature of $37^{\circ} \mathrm{C}$, as recommended by the ATCC. Cells were dispensed into new flasks with subculturing every 6-8 days. The growth medium was changed every 3 days.

Culturing of human renal adenocarcinoma cells. The propagation of the human renal cell adenocarcinoma cells was carried out in Eagle's Minimum Essential Medium supplemented with $2 \mathrm{mM}$ glutamine adjusted by the addition of $1.5 \mathrm{~g} / \mathrm{l}$ sodium bicarbonate, $1 \mathrm{mM} 90 \%$ sodium pyruvate and $10 \%$ FBS (Sigma Chemical Co.) with $5 \% \mathrm{CO}_{2}$ at a temperature of $37^{\circ} \mathrm{C}$, as recommended by the ATCC. Cells were dispensed into new flasks with subculturing every 6-8 days. The growth medium was changed every 3 days.

SFRP-3 ELISA. Analysis of sFRP-3 was carried out using the DuoSet sFRP-3 immunoassay (R\&D Systems, Inc., Minneapolis, MN, USA), a 6-hour solid phase ELISA designed to measure sFRP-3 levels in cell culture. In this assay, an immobilized capture antibody specific for sFRP-3 binds to sFRP-3 using a standard streptavidin conjugated to horseradish peroxidase. This ELISA specifically recognizes SFRP-3 without cross-reactivity or interference with FRP-1, FRP-4 and sFRP-2. The sFRP-3 ELISA was calibrated against a highly purified NSO-expressed recombinant human SFRP-3 (R\&D Systems, Inc). The standard curve for this assay was calculated using a four-parameter logistic (4-PL) curve fit.

sFRP-3 research protocol. The human colorectal cancer, pancreatic carcinoma and renal adenocarcinoma cells were subcultured for $24 \mathrm{~h}$, then $\sim 5,000$ cells of each line in $50 \mu \mathrm{l}$ of their respective media were seeded in 96-well plates with $50 \mu 1$ media containing $10 \mu \mathrm{M}, 1 \mu \mathrm{M}, 100 \mathrm{nM}, 10 \mathrm{nM}$, $1 \mathrm{nM}$ and $100 \mathrm{pM}$ concentrations of each of the four cardiac hormones separately (i.e. six concentrations of four cardiac hormones measured six times at each concentration; $n=6$ for each concentration). Standards from R\&D Systems were diluted using Reagent Diluent and added to blank wells to serve as reference points of known sFRP-3 concentrations. In this assay, absorbance was examined at a $540 \mathrm{~nm}$ wavelength using a 96-well Gen5, Synergy Mx microplate reader (BioTek,

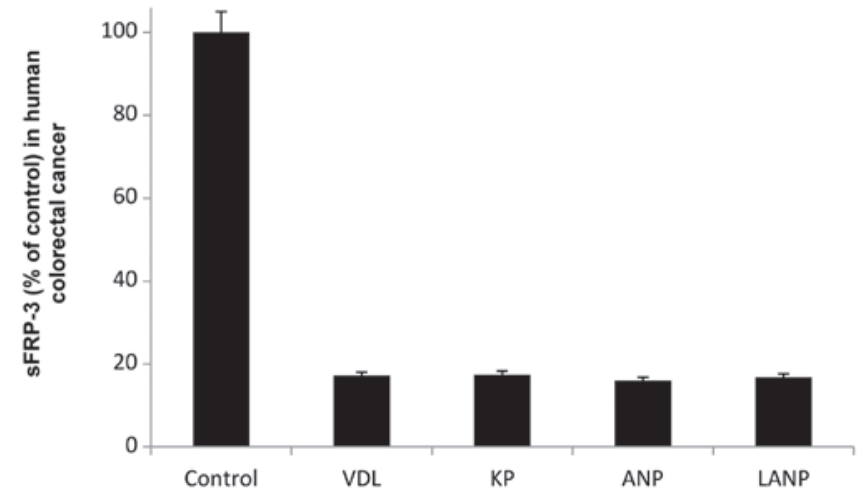

Figure 1. Vessel dilator (VDL), kaliuretic peptide (KP), atrial natriuretic peptide (ANP) and long-acting natriuretic peptide (LANP) maximally reduced the level of secreted frizzled-related protein 3 (sFRP-3) (in $\mathrm{pg} / \mathrm{ml}$ ) in human colorectal cancer cells by $83 \%, 83 \%, 84 \%$ and $83 \%$, respectively. Each of these reductions was significant at $\mathrm{P}<0.0001$ when evaluated by the Student's t-test for unpaired values. Each bar represents the mean \pm SEM of 32 determinations for the control and 6 determinations for the experimental groups.

Winooski, VT, USA) set according to the parameters recommended by the manufacturer. There were 32 controls for each cell line $(\mathrm{n}=32)$ and six experimental determinations for each of the six concentrations of the four cardiac hormones in the three cancer cell lines $(\mathrm{n}=6)$.

Statistical analysis. Data are expressed as the means \pm SEM. The statistical analyses of the data were performed using a Student's t-test for unpaired values. $\mathrm{P}<0.05$ was considered to indicate a statistically significant difference.

\section{Results}

Inhibition of sFRP-3 in human colorectal cancer cells. An $83 \%$ $(\mathrm{P}<0.0001)$ reduction of the $\mathrm{sFRP}-3$ level was observed in the human colorectal cancer cells following treatment with $100 \mathrm{nM}$ vessel dilator (Fig. 1). KP and ANP caused maximal reductions of the sFRP-3 level in the human colorectal cancer cells of $83 \%$ and $84 \%$ respectively, both at a concentration of $100 \mathrm{nM}$ $(\mathrm{P}<0.0001)$, while LANP caused a maximal decrease of $83 \%$ $(\mathrm{P}<0.0001)$ at a concentration of $10 \mu \mathrm{M}$ (Fig. 1). In the human colorectal cancer cells, each of the cardiac hormones caused a similar significant $(\mathrm{P}<0.0001)$ decrease in the sFRP-3 level.

Inhibition of sFRP-3 in human pancreatic carcinoma cells. Vessel dilator maximally reduced the sFRP-3 level by $77 \%$ $(\mathrm{P}<0.0001)$ in the human pancreatic cancer cells at its $1 \mathrm{nM}$ concentration (Fig. 2). KP and ANP also maximally reduced the sFRP-3 level in the human pancreatic cancer cells by $77 \%$ $(\mathrm{P}<0.0001)$, the former at a concentration of $100 \mathrm{pM}$ and the latter at concentrations of $100 \mathrm{nM}$ and $1 \mathrm{nM}$ (Fig. 2). LANP reduced the sFRP-3 level in the human pancreatic cancer cells by $78 \%$ at its $1 \mathrm{nM}$ concentration $(\mathrm{P}<0.0001$; Fig. 2$)$. Each of the cardiac hormones had a similar marked ability to reduce the sFRP-3 level in the human pancreatic cancer cells.

Inhibition of SFRP-3 in human renal adenocarcinoma cells. Vessel dilator decreased the sFRP-3 level in the human renal cancer cells by $68 \%$ at a concentration of $1 \mu \mathrm{M}(\mathrm{P}<0.0001)$, and 


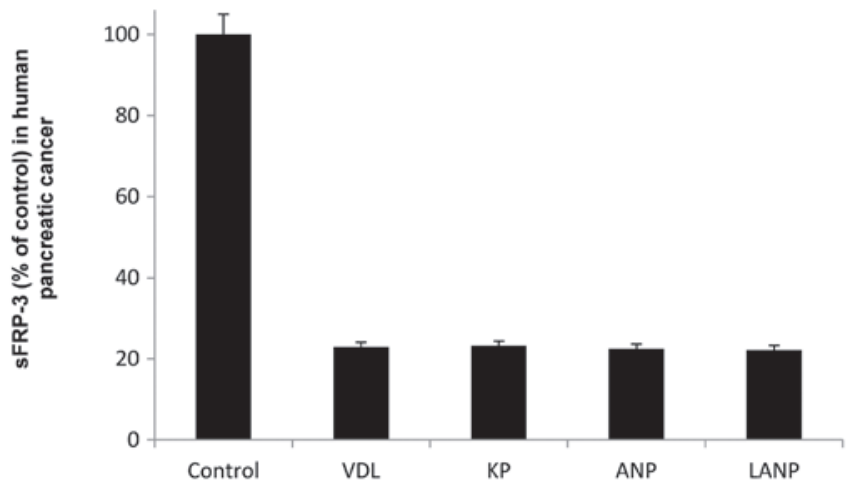

Figure 2. Secreted frizzled-related protein 3 (sFRP-3) in human pancreatic cancer cells was maximally reduced by $77 \%, 77 \%, 77 \%$ and $78 \%$ by vessel dilator (VDL), kaliuretic peptide (KP), atrial natriuretic peptide (ANP) and long-acting natriuretic peptide (LANP), respectively. Each of these reductions was significant at $\mathrm{P}<0.0001$ when evaluated by the Student's t-test for unpaired values. Each bar represents the mean \pm SEM of 32 determinations for the control and 6 determinations for the experimental groups.

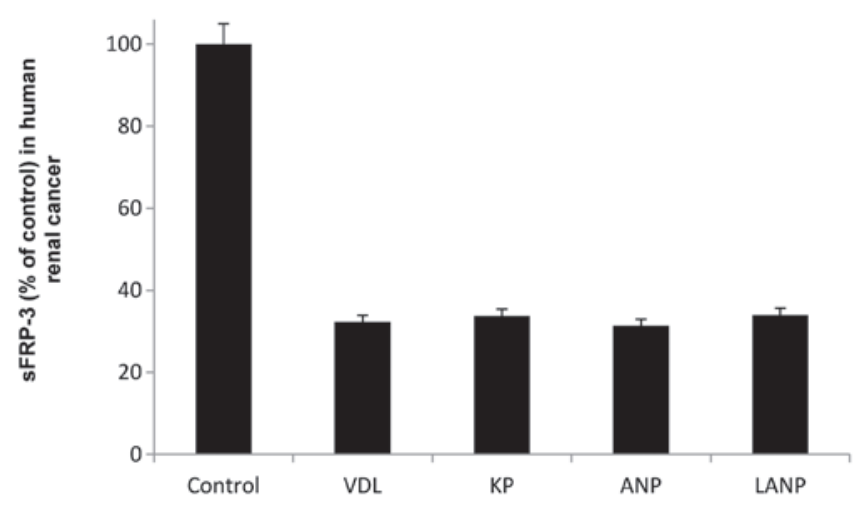

Figure 3. The level of secreted frizzled-related protein 3 (sFRP-3) in human renal adenocarcinoma cells was maximally reduced by $68 \%, 66 \%, 68 \%$ and $66 \%$, by vessel dilator (VDL), kaliuretic peptide (KP), atrial natriuretic peptide (ANP) and long-acting natriuretic peptide (LANP), respectively. Each of these reductions was significant at $\mathrm{P}<0.0001$ when evaluated by the Student's t-test for unpaired values. Each bar represents the mean \pm SEM of 32 determinations for the control and 6 determinations for the experimental groups.

KP maximally reduced the sFRP-3 level by $66 \%(\mathrm{P}<0.0001)$ at the same concentration. The maximal decrease in the sFRP-3 level of the human renal cancer cells following treatment with ANP was $68 \%(\mathrm{P}<0.0001)$ at a concentration of $10 \mathrm{nM}$ and following treatment with LANP was $66 \%(\mathrm{P}<0.0001)$ at a concentration of $100 \mathrm{nM}$ (Fig. 3). In the human renal cancer cells, the abilities of each of the cardiac hormones to inhibit human sFRP were not significantly different as each caused similar significant decreases in the sFRP-3 level. The four cardiac hormones caused similar marked decreases in the sFRP-3 levels of the human colorectal, pancreatic and renal cancer cells (Figs. 1-3).

\section{Discussion}

It has been reported that $\mathrm{SFRP}-3$ promotes renal cancer growth when injected into nude mice (8). sFRPs have also been linked to tumor promotion in other types of cancer (9). It has been suggested (7) that the elevated sFRPs in various types of cancers may be valuable therapeutic targets. The present investigation demonstrates that vessel dilator, KP, ANP and LANP decreased the levels of sFRP-3 by $77-78 \%$ in human pancreatic cancer cells, 83-84\% in human colorectal cancer cells and 66-68\% in human renal cancer cells. These significant reductions of sFRP-3 suggest that it is a target of the four cardiac hormones in a variety of types of cancer. With respect to the mechanism by which the reduction of sFRP-3 levels by the cardiac hormones leads to their anticancer effects, the ability to inhibit sFRP-3, the active CRD of the Frizzled receptor (3), blocks the propagation of the signal responsible for causing cancer cell growth.

It is important to note that the reductions in sFRP-3 levels (up to $84 \%$ ) are similar in magnitude to the $80 \%$ elimination of human pancreatic cancers in mice and $86 \%$ elimination of human small-cell lung cancers growing in mice $(10,11)$. The decrease in FRP-3 is also similar in magnitude (\% decrease) in cell number of cancer cells in vitro (13-15). These observations suggests that sFRP-3 is an important therapeutic target of the cardiac hormones in mediating their anticancer effects (9-11). Furthermore, this target is present in more than one cancer type, and the present study demonstrates that SFRP-3 is a treatment target in human pancreatic, renal and colorectal cancers for each of the four agents evaluated.

\section{Acknowledgements}

The authors thank Karen Murphy for excellent secretarial assistance. The present study was supported in part by grants from the James and Esther King Florida Biomedical Research Program, the Florida Department of Health and the Mama Mare Breast Cancer Foundation.

\section{References}

1. Dann, CE, Hsieh JC, Rattner A, Sharma D, Nathans J and Leahy DJ: Insights into Wnt binding and signalling from the structures of two Frizzled cysteine-rich domains. Nature 412: 86-90, 2001.

2. Malbon CC: Frizzleds: new members of the superfamily of G-protein-coupled receptors. Front Biosci 9: 1048-1058, 2004.

3. Rattner A, Hsieh JC, Smallwood PM, Gilbert DJ, Copeland NG, Jenkins NA and Nathans J: A family of secreted proteins contains homology to the cysteine-rich ligand-binding domain of frizzled receptors. Proc Natl Acad Sci U S A 94: 2859-2863, 1997.

4. Lin K, Wang S, Julius MA, Kitajewski J, Moos M Jr and Luyten FP: The cysteine-rich frizzled domain of Frzb-1 is required and sufficient for modulation of Wnt signaling. Proc Natl Acad Sci U S A 94: 11196-11200, 1997.

5. Xu YK and Nusse R: The Frizzled CRD domain is conserved in diverse proteins including several receptor tyrosine kinases. Curr Biol 8: R405-R406, 1998.

6. Kawano Y and Kypta R: Secreted antagonists of the Wnt signalling pathway: J Cell Sci 116: 2627-2634, 2003.

7. Bovolenta P, Esteve P, Ruiz JM, Cisneros E and Lopez-Rios J: Beyond Wnt inhibition: new functions of secreted Frizzled-related proteins in development and disease. J Cell Sci 121: 737-746, 2008.

8. Hirata H, Hinoda Y, Ueno K, Majid S, Saini S and Dahiya R: Role of secreted Frizzled-related protein 3 in human renal cell carcinoma. Cancer Res 70: 1896-1905, 2010.

9. Rubin JS, Barshishat-Kupper M, Feroze-Merzoug F and Xi ZF: Secreted WNT antagonists as tumor suppressors: pro and con. Front Biosci 11: 2093-2105, 2006.

10. Eichelbaum EJ, Sun Y, Alli AA, Gower WR Jr and Vesely DL: Cardiac and kidney hormones cure up to $86 \%$ of human small-cell lung cancers in mice. Eur J Clin Invest 38: 562-570, 2008 . 
11. Vesely DL, Eichelbaum EJ, Sun Y, Alli AA, Vesely BA, Luther SL and Gower WR Jr: Elimination of up to $80 \%$ of human pancreatic adenocarcinomas in athymic mice by cardiac hormones. In Vivo 21: 445-451, 2007.

12. Vesely DL, Vesely BA, Eichelbaum EJ, Sun Y, Alli AA and Gower WR Jr: Four cardiac hormones eliminate up to two-thirds of human breast cancers in athymic mice. In Vivo 2: 973-978, 2007.

13. Vesely BA, Eichelbaum EJ, Alli AA, Sun Y, Gower WR Jr and Vesely DL: Urodilatin and four cardiac hormones decrease human renal carcinoma cell numbers. Eur J Clin Invest 36: 810-819, 2006.
14. Gower WR, Vesely BA, Alli AA and Vesely DL: Four peptides decrease human colon adenocarcinoma cell number and DNA synthesis via cyclic GMP. Int J Gastrointest Cancer 36: 77-87, 2005.

15. Vesely BA, McAfee Q, Gower WR Jr. and Vesely DL: Four peptides decrease the number of human pancreatic adenocarcinoma cells. Eur J Clin Invest 33: 998-1005, 2003. 